\title{
Short Article
}

\section{MONOCLONAL ANTIBODIES: A WITNESS SEMINAR IN CONTEMPORARY MEDICAL HISTORY}

\author{
by
}

\author{
E. M. TANSEY and P. P. CATTERALL *
}

"Such cultures could be valuable for medical and industrial use." Thus read the final sentence of an immunological paper published in Nature in 1975 by the Argentinian born César Milstein, and his German post-doctoral fellow, Georges Köhler. Entitled 'Continuous cultures of fused cells secreting antibody of predefined specificity', the paper, from Milstein's lab in the MRC Laboratory of Molecular Biology in Cambridge, announced the discovery of monoclonal antibodies. ${ }^{1}$

The later debates and recriminations about the apparent "failure" of British science and technology to exploit this invention to commercial advantage threw monoclonal antibodies into a public prominence rarely achieved by scientific discoveries. To a large extent this has overshadowed the significance of the original research and the context in which it was undertaken.

The history of that discovery was the subject of a witness seminar held by the Wellcome Trust's History of Twentieth Century Medicine Group in association with the Institute of Contemporary British History, under the Chairmanship of Sir Christopher Booth. Many of the key players gathered together to discuss and debate issues associated with the scientific work, its later exploitation and the nature of scientific discovery. They included Milstein and Köhler, who shared a Nobel Prize in 1984 for their discovery, their former colleagues, past and present members of staff of the Medical Research Council and journalists and historians.

Antibodies are the proteins produced by lymphocytes that recognize and bind to foreign substances or antigens in the blood and neutralize them. Each antibody is specific for one antigen, and is produced by a particular kind of lymphocyte. Hence the latter are immensely diverse, and purifying or extracting a single, defined, antibody was practically impossible. Monoclonal antibodies are just one, defined and pre-determined kind of

* E. M. Tansey, BSc, PhD, PhD, Wellcome Institute for the History of Medicine, 183 Euston Road, London NW 1 2BE; P. P. Catterall, MA, PhD, Institute for Contemporary British History, 50 Gordon Square, London WCIH OPQ.

We are grateful to the Wellcome Trust for supporting this seminar, to all the participants, and to Drs John Galloway, Nick Russell, Stephen Lock and Guil Winchester for their help.

' G. Köhler and C. Milstein, 'Continuous cultures of fused cells secreting antibody of predefined specificity', Nature, 1975, 256: 495-597. 


\title{
Monoclonal antibodies
}

antibody, produced from a pure single-cell culture line. Their availability had a major impact on the development of immunology, and on technological and commercial developments.

The meeting was introduced by Dr Robert Bud, Head of Life and Environmental Sciences at the Science Museum, who remarked that, whilst contemporary history offers a rare interaction between subject and viewer, the relationship can be as daunting as it is exciting. But, he emphasized, that relationship

\begin{abstract}
provides an opportunity for us to have a much more interesting interchange and identification of what are already understood to be momentous and important changes and developments. Already it is clear that the emergence of biotechnology as a whole is one of the big shifts in late twentieth century technology.
\end{abstract}

The term "new biotechnology" had been popularised by the 1984 Office of Technology Assessment Report, Commercial Biotechnology, and this "new biotechnology" stood on three legs. One, which had quickly been forgotten, comprised new fermentation technologies. The other two, much better known, were recombinant DNA and hybridoma, specifically monoclonal antibody, technology.

Bud then examined the contexts of the monoclonal antibody story. Firstly, the tissue culture work with myelomas and techniques of cell fusion had all been in use in César Milstein's laboratory in the Medical Research Council's Laboratory of Molecular Biology in Cambridge, one of the world's premier bio-medical research Institutes. When the significance of the achievement was recognized, in the 1980s, questions had immediately been raised as to who had done the work, typifing the complexities of real scientific discoveries, which are often difficult to explain to the public.

Secondly [Bud continued], all this happened at a time when other exciting things were happening in biotechnology. In February 1975, the Asilomar meeting had considered how one could control the safety of work on recombinant DNA technology. By June 1976 the NIH had identified regulations by which this work could proceed and by 1976 onwards enormous amounts of commercial enthusiasm went, particularly in the States, into biotechnology into recombinant DNA technology. The outcome was many companies, Genentech was one, Biotech another. So, Milstein and Köhler’s paper appeared in the midst of technological excitement. This had particular meaning in Britain because of a local history of technological disappointment following a scientific breakthrough. There was the memory of the discovery of penicillin and the apparent failure of Britain to cash in on it subsequently. ${ }^{2}$

Thus Bud's introduction pointed to two particular aspects of this story for discussion. Firstly, the nature of the scientific discovery itself, the circumstances and contexts within which the crucial experiments were performed. Secondly, the commercial application and technology transfer of monoclonal antibodies, which form the basis of a separate report. ${ }^{3}$

\footnotetext{
2 The Asilomar Conference resulted from concern within the biological community about the possible consequences of genetic engineering. A brief review of the meeting and its decision is given in R. Bud, The use of life: a history of biotechnology, Cambridge University Press, 1993, esp. pp. 175-6.

${ }^{3}$ P. P. Catterall and E. M. Tansey, 'Technology transfer in Britain: the case of monoclonal antibodies", Comtemporary Record (forthcoming).
} 


\section{E. M. Tansey and P. P. Catterall}

Agreeing with the importance of these issues, Milstein suggested that the scientific atmosphere and technical competence of the Laboratory of Molecular Biology at Cambridge had been crucial. He added,

Perhaps even more important is another issue, one that has not been mentioned so far, and that is why the experiments worked so smoothly and successfully. To what extent were there elements of coincidence, just pure luck, and to what extent were the experiments done correctly and logically? I think there were both.

Milstein also wondered whether the applications of the hybridoma technology had been clear in their own minds, or in others' at the time of the discovery. When he and Köhler had been writing the original paper and considering the final sentence, they had been hesitant in emphasizing the potential. After much discussion, they had included the remark because they were convinced that the technique would prove valuable, although he continued,

I am not saying that we discussed how many zeroes it would be worth at the end of the equation. I confess I would never have dreamt the number of zeroes that actually appeared, probably neither did Georges.

The scientific background of the work was recalled by Professor Köhler, who had moved to Milstein's lab as a young post-doctoral fellow, having completed a $\mathrm{PhD}$ on antibody heterogeneity at Basle. The mid-1970s was a period when several ideas about antibody generation were prominent, especially the "somatic mutation" theory promoted by Niels Jerne, and the more conventional "germline" hypothesis. Milstein's lab was experienced in studying myelomas, tumours of the immune system, in mice. Using a technique developed earlier by Potter, they had established a culture of rapidly proliferating tumour cells that produced immunoglobulins or antibodies. With Dick Cotton, Milstein had examined the structure of immunoglobulins, which are composed of four chains: 2 heavy chains which, like the upright of the letter "Y", constitute the antibody's constant region and two light chains, which in association with terminal parts of the heavy chains, like the extended arms of the letter "Y", form the variable region of the immunoglobin. Using rat/mouse hybrid myelomas, Milstein and Cotton had shown that the regions of the immunoglobulin were always of one species, although the chains could be hybrids of both.

The reputation of, and techniques available in, Milstein's lab had drawn Köhler to Cambridge.

It was the story of a young scientist looking for a good laboratory, which was exactly what I found in César Milstein's laboratory. He was working with myeloma P3 which were growing in culture and had produced the first mutants. I was fascinated by the idea that you could generate a diversity of antibody specificities by starting with one gene and diversifying it by mutation.

The technical problem, however, was that myelomas produced antibodies of unknown specificity. Milstein suggested that Köhler should investigate the antigen specificity of his myeloma P3 antibodies. Instead, Köhler turned the problem around, trying to generate 


\section{Monoclonal antibodies}

antibodies with defined specificity. Thus, instead of fusing two myelomas, he decided to fuse one with an antibody-producing cell, a B-lymphocyte. Milstein, Köhler stressed, was prepared to listen. "He did not dismiss it as out of reach, the strange idea of a post-doc, but he sat down and we discussed the possibilities."

Köhler decided to fuse mouse spleen cells, which are rich in B lymphocytes, with mouse myeloma cells. Although a rare product of the fusion technique the resulting hybrid cell, or hybridoma, was extremely important. By raising the levels of antibody through pre-immunization, and then fusing the spleen and myeloma cells, the hybridoma combined two attributes: the long-living properties of the myeloma, and the specificity of the antibody. For the first time, then, large quantities of a pure, specified antibody could be produced. The first experiment succeeded, Köhler remarking laconically, "We thought we should make a hybrid, and so I did the fusion, and it worked out very nicely".

This discovery revolutionized the study of immunity and the immune response, and generated clinical applications. These developments, for which Köhler and Milstein's discovery was freely available, later led to much debate, discussion and recrimination about the absence of patent protection, an aspect which was discussed by Dr David Secher, a contemporary of Milstein and Köhler in Cambridge, and later the lab's first industrial liaison officer, and Dr David Owen, the current director of industrial collaboration of the MRC.

The scientific aspects were discussed by Sir James Gowans, the distinguished immunologist and subsequently, in 1977, the Secretary of the MRC, who recalled the impact of the first announcement of the work.

I don't remember being shattered. I think I was actually at the first meeting where César talked about his results and I remember being mightily intrigued. I thought it was extremely ingenious and very interesting and one went away and talked about it and told one's friends what César had been up to. Some time later when the commercial possibilities became clear, I remember thinking back to the days when I listened to the lecture. One was not thinking at the time when one was in the lecture that there was a vast catalogue of diagnostic reagents just waiting on the horizon, or perhaps even therapy. These possibilities were certainly not mentioned in the lecture. It was a very interesting, biologically-illuminating bit of science, but also a method for producing very pure antibodies, which of course one could see would be important for research. It was a beautiful piece of science. The media often presents science as a mixture of breakthroughs and disasters but it really doesn't work like that: science is usually a slow chipping away and every now and again there is a big chip and this was a big chip which we all sat up and took notice of.

Another eminent immunologist Ita Askonas, commented,

I remember the excitement, although the report of the first antigen specific hybridoma was not shattering. It was not the first time that people thought about trying to do cell-cell fusions, but this was the first time it was successful. The only real surprise was the fact that selection of hybridomas producing monoclonal antibodies worked so well and reproducibly. I have to admit-and I think César could tell this story too-that Alan Williamson and myself had been working some years before, attempting to get monoclonal antibodies by transferring B-cell clones in vivo. That worked well through quite a few transfer generations until suddenly the clones started to die-senescence. 


\section{E. M. Tansey and P. P. Catterall}

We tried to fuse the clones with transformed cells, using Littlefield's method, but without success. Therefore I was absolutely thrilled to hear of the achievements of César's laboratory. ${ }^{+}$

But, after the first successes, the next set of experiments went badly or failed completely. Köhler was appointed to the Institute of Immunology at Basle, but neither there nor in Cambridge would the experiments work. He and Milstein recalled hours on the telephone and the frequent exchange of serum and cell preparations, Milstein going on to comment,

the reasons actually, probably were different in both cases, and in ours it was quite an unbelievable situation. We were using something called HAT medium, which is a medium specially for the selection of hybrids, and in preparation of this medium we kept it in concentrated form. Now, just before Georges left the lab the concentrated solution was finished and one of my students prepared a new solution, and this was a concentrated solution. From there dilutions were prepared here and there in several stages, and it transpired six months later-it took us six months to find out-that that solution, for some reason which we never found out, was toxic, so instead of selecting cells we were killing them. That was certainly not the case in your [Köhler's] lab. I don't know why in your case, it must have been something like that.

The time-course for the success to become apparent was also emphasized by David Secher:

The first experiment worked, but then there were experiments that did not work, for reasons that were not obvious, and there was quite a long time when it did not work and so, with hindsight of course, there was not a single shattering moment when the paper was published. Of course, had it not turned out to be reproducible or had it not turned out that medicine and technology would be so important we would not now be looking back and talking about when was that single moment?

Many of the seminar participants emphasized that the invention of monoclonal antibodies relied on many factors: the availability of relevant techniques in an established laboratory; the conjunction of a junior and a senior scientist with synergistic skills, interests and experience, enabling a new idea to be tried and developed; and the way in which scientific discoveries build and extend the work of previous generations. Several, especially the two Nobel Laureates themselves and David Secher, stressed the importance of pursuing and supporting basic research, and the particular value of the supportive ambience in the Laboratory of Molecular Biology.

Milstein's own career, from arriving at the LMB as a young Argentinian scientist, had benefited greatly from the lab's traditions. Employed to work with Fred Sanger, the proposed collaboration had not been successful, and Sanger encouraged and supported Milstein in pursuing his own ideas, "Do good experiments and don't worry about anything else", he told his young protégé. No one had stopped him crossing disciplinary boundaries or developing new ideas. Milstein stressed that dedicated research institutes are

${ }^{4}$ J. W. Littlefield, 'Selection of hybrids from matings of fibroblasts "in vitro" and their presumed recombinance', Science, 1964, 145: 709-10; this was the standard technique to produce hybrid cells in many labs, including Askonas' at the National Institute for Medical Research. 


\section{Monoclonal antibodies}

critical for the development of good research, suggesting that "laziness is the mother of good science". In a teaching environment a scientist might be tempted, when faced with obstacles and difficulties, to devote more of his resources to teaching. But in a pure research environment, such as the LMB, a scientist had to think and think to get out of his impasse. And both Milstein and Köhler discussed the questions that arose from their collaboration. Did one make a more substantial contribution than the other? Köhler, remembering his arrival in Cambridge, cited the ease of communicating with Milstein as one of the attractions of the lab. Milstein agreed that this was a major reason for accepting the younger man into his lab,

Why did I accept him?.I had two candidates, and the reason I accepted him was because it was clear that there was something communicating in our minds. Somehow I felt that we were talking the same language.

Questions about the respective roles of the two scientists had become more explicit when they shared a Nobel Prize; they had prepared a joint statement to explain their collaboration.

We agree that both conception and execution of the work was the result of close collaboration between us, with the skilled technical assistance of Shirley Howe. We are further convinced that the combined effect which results from such close collaboration was of a synergistic nature, synergistic effects taken to mean, as with monoclonal antibodies, effects which result from the combined action of two but which cannot be produced by the two separately. We both have a most pleasant memory of an exciting period in which a word, a comment, or a passing remark made by one had a resonant effect on the other. We do not want such happy memories, which have sealed a close friendship, to be disturbed by superficial interpretations of our individual recollections. It was a collaborative work. It was a collaborative paper. We do not want to make further comments. 